\title{
ПРЕДМЕТ УГОЛОВНО-ПРАВОВОГО РЕГУЛИРОВАНИЯ С ПОЗИЦИИ КАТЕГОРИЙ ОБЩЕГО, ОСОБЕННОГО И ЕДИНИЧНОГО 1
}

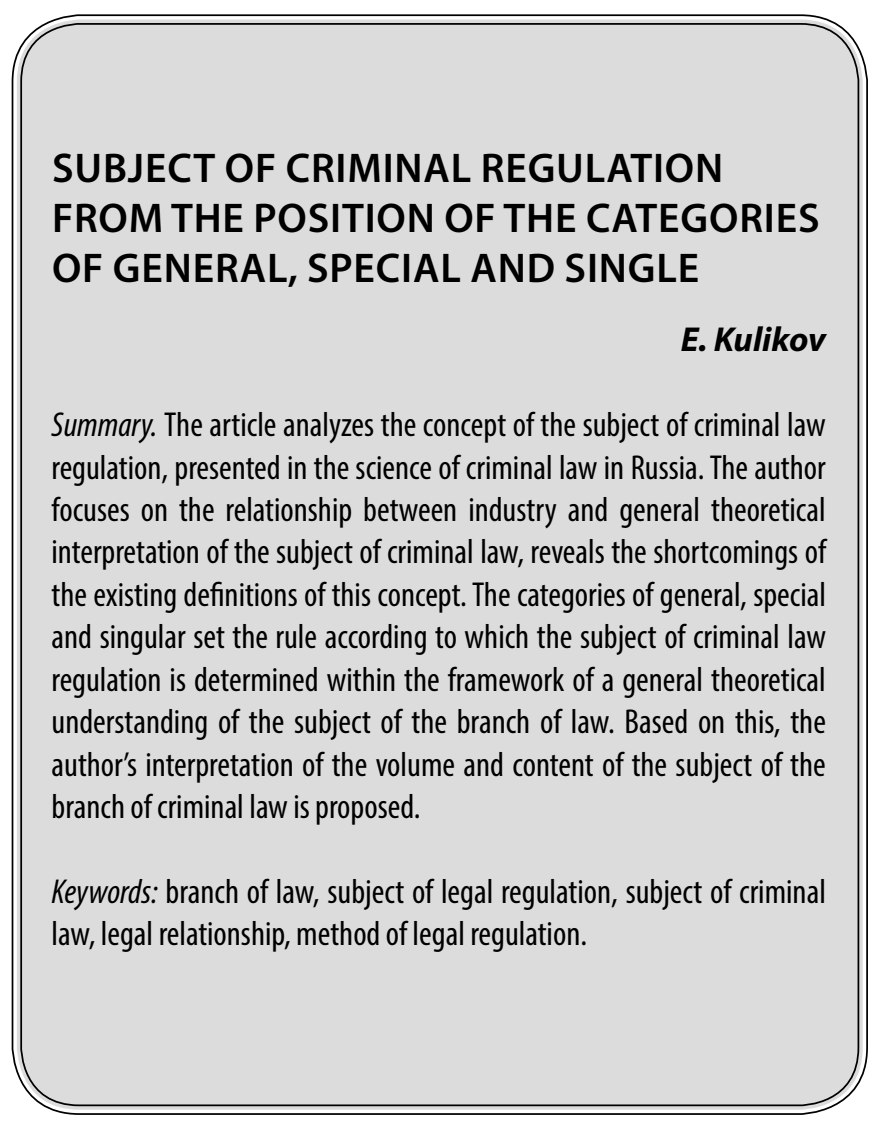

K атегории общего, особенного и единичного образуют триаду уровней познания социальных и природных явлений, выступают одним из показателей системности явлений, их взаимосвязи и взаимодействия между собой. При этом, в отличие, например, от другой категориальной триады “количество - качество - мера", достаточно стабильной по своей сути, общее, особенное и единичное подвижны, одно и то же понятие, например, выступая в одном контексте общим, для другого является особенным, а в третьем вообще показывает единичное явление. Разные «ступени абстракции» при познании природных, социальных, в т.ч., правовых явлений, в свою очередь, предполагают учет взаимосвязи названных категорий между собой, их взаимообусловленности. Так, невозможно игнорировать ту закономерность, согласно которой общее не суще-

\author{
Куликов Егор Алексеевич \\ К.ю.н., дочент, Алтайский государственный \\ университет (Барнаул) \\ kulikoveg@yandex.ru
}

Аннотация. В статье анализируется понятие предмета уголовно-правового регулирования, представленное в науке уголовного права России. Автор делает акцент на соотношении отраслевой и общетеоретической трактовки предмета уголовного права, выявляет недостатки существующих определений данного понятия. Категории общего, особенного и единичного задают правило, согласно которому предмет уголовно-правового регулирования определяется в рамках общетеоретического понимания предмета отрасли права. Исходя из этого предлагается авторская трактовка объема и содержания предмета отрасли уголовного права.

Ключевые слова: отрасль права, предмет правового регулирования, предмет уголовного права, правоотношения, метод правового регулирования.

ствует само по себе, но только лишь проявляясь в единичном, а с другой стороны, если единичное относится к этому общему, то оно должно включать общее в себя в полном объёме. Особенное же как самостоятельная фигура познания появляется лишь тогда, когда между общим и единичным существует какое-то промежуточное звено. В связи с этим точнее говорить о категориях общего (особенного) и единичного.

В советской философии, получившей наименование "философия диалектического материализма" категориям диалектики, в том числе и рассматриваемым в настоящей статье, уделялось значительное внимание. А.П.Шептулин посвятил специальную работу диалектике единичного, особенного и общего. Данные категории, начиная, по меньшей мере, с «Науки логики» Г.В.Ф. 
Гегеля, относятся к учению о понятии, или субъективной логике. Юридическая наука, право, юриспруденция, как верно указывает А.Ф. Черданцев, имеет дело преимущественно с идеальными объектами. Юридические понятия, в том числе наиболее фундаментальные из них как на уровне теории права, так и в отраслевых правовых науках, являются именно такими идеальными объектами. При этом качество определения содержания того или иного понятия обусловлено адекватностью отражения в этом понятии стоящей за ним объективной реальности. Соблюдение закономерностей познания, в т.ч. связанных с системой категорий диалектики, выступает необходимым условием адекватности такого отражения.

Непосредственно статья посвящена проблемным аспектам понимания предмета уголовно-правового регулирования, поскольку он охватывает корреспондирующую уголовному праву социальную реальность, а также определяет метод уголовно-правового регулирования и определяется методом уголовно-правового регулирования. Кроме того, наличие собственного самостоятельного предмета правового регулирования выступает необходимым компонентом отраслевого статуса уголовного права. С другой стороны, важность и фундаментальный характер данного понятия не снимает дискуссионности его определения, сложности и неоднозначности его трактовки разными авторами, а также некоторых, порой, в зависимости от подхода конкретного ученого, весьма существенных расхождений в общем понимании предмета правового регулирования в теории права, и предмета уголовно-правового регулирования в науке уголовного права.

Необходимость уточнения понятия предмета уголовно-правового регулирования с позиции категорий общего, особенного и единичного определяется ещё и тем, что точный смысл и адекватное действительности его восприятие определяющим образом влияет на качество правового регулирования. Как сказал ещё в глубокой древности великий китайский мудрец Конфуций, «если имена неправильны, то слова не имеют под собой оснований, а если слова не имеют под собой оснований, то дела не могут осуществляться» [9, с. 32]. В этой связи очень важно исходить из общего понимания предмета правового регулирования, поскольку, будучи общим, оно в полном объёме выражается в особенном - предмете уголовно-правового регулирования.

В общей теории права разработаны критерии обособления отраслей права. Обобщенно они определяются как предмет и метод правового регулирования, либо метод разделяется на ряд самостоятельных элементов [11, с. 24-25]. Кроме того, отдельные ученые называют внеюридические критерии обособления, характеризующие национально-правовую специфику системы права [14, с. 403]. Подробный перечень критериев самостоятельности отрасли права, таким образом, может включать: собственный отраслевой предмет правового регулирования, относительно обособленный от предметов других отраслей; собственный метод отраслевого регулирования как комбинация специфических отраслевых юридических средств; система источников отрасли права (иногда говорят, достаточно разработанная нормативно-правовая основа отрасли); особый процедурный порядок применения отраслевых норм (грубо говоря, собственный комплекс процессуальных норм); система органов государственной власти, применяющих преимущественно нормы данной отрасли права; отраслевые правовые принципы; своеобразные отраслевые правоотношения, в т.ч. особый субъектный состав и набор объектов; сложившиеся в системе правовые традиции; собственный вид юридической ответственности; самостоятельная юридическая наука и учебная дисциплина.

В наибольшей степени отраслевой статус определяют предмет и метод регулирования, система источников как юридическая форма метода, а также ответственность как средство обеспечения его реализации. Ю.Е. Пудовочкин, например, пишет, что «пределы уголовно-правового регулирования во многом заданы предметом и методом уголовного права, которые в совокупности являются основанием для выделения уголовного права в качестве самостоятельной отрасли в правовой системе России» $[18$, с. 149]. Система взаимосвязей общего, особенного и единичного предполагает, что названные феномены, взятые на уровне уголовного права, уточняют и конкретизируют их общеправовую трактовку, но при этом находятся в ее рамках, включают все общие черты, имеют свои особенности в пределах общих черт. Это достаточно простое и понятное для любого квалифицированного юриста утверждение, однако, при обращении от теории права к отраслевым наукам далеко не всегда прослеживается. Рассмотрим, как обстоит дело в уголовно-правовой науке России.

Уголовное право - одна из старейших отраслей, корни которой восходят ещё к обычному праву догосударственных обществ. Определение ее предмета не составляет нового знания для юридической науки. Можно сказать, что вопрос «что есть предмет уголовного права как отрасли права?» на сегодняшний день является риторическим. С другой стороны, когда мы уточняем этот вопрос, и начинаем анализировать, что именно есть предмет отраслевого правового регулирования для уголовного права, особенно при сопоставлении с пониманием предмета правового регулирования в общей теории права, ответ утрачивает былую определенность. И.Я. Козаченко говорит о том, что «установившиеся в отечественной науке уголовного права взгляды на предмет правового регулирования нельзя признать адекватны- 
ми уголовно-правовым реалиям социальной жизни» [7, с. 83]. На дискуссионность и неоднозначность в понимании предмета уголовного права указывает Н.В. Генрих. «Прежде всего следует отметить, что полисемия термина «уголовное право», допускающая его использование для обозначения одновременно отрасли научного знания, отрасли права и учебной дисциплины, предполагает возможность и необходимость выделения предмета каждого из обозначенных явлений» [4, с. 70]. О сложностях, связанных с определенной неадекватностью понимания предмета и метода уголовного права социальным реалиям, пишет М.В. Бавсун [2, с. 570-580]. Правда, он делает акцент не на правовом регулировании, а на проявлениях т.н. «дисциплинарной» власти, которые были описаны ещё в работах М. Фуко [17, с. 358-362], как более эффективных, нежели уголовное наказание, средствах воздействия на преступность.

Можно предположить, что сложности с определением предмета уголовного права вызываются двухуровневым характером отношений в уголовно-правовой сфере, В.Д.Филимонов выделяет, например, охраняемые и охраняющие отношения, где «охраняемое уголовным правом отношение состоит в потребности конкретного человека жить, обладать здоровьем и телесной неприкосновенностью и соответствующей ей необходимости для других лиц воздерживаться от действий, способных причинить им вред», а охраняющее общественное отношение «заключается в потребности государства обеспечить охрану жизни, здоровья и телесной неприкосновенности гражданина и в необходимости всех других членов общества воздерживаться от причинения им вреда» [16, с. 32-33]. Подобного рода позиции порождают вопрос о том, как необходимо понимать предмет уголовного права как отрасли права, если в многих случаях оно охраняет своими средствами социальную реальность, которая уже урегулирована нормами других отраслей права.

При всех вопросах, которые вызывает подход Н.В. Генрих к предмету уголовного права, следует признать весьма удачным определение, которое она дает этому понятию. «Предметом уголовно-правового регулирования необходимо признать группу однородных общественных отношений, которые могут и должны регулироваться уголовным законодательством, нормы которого создают определенные модели поведения их участников при наступлении тех или иных юридических фактов» [4, с. 80-81]. Представленная дефиниция удивительно точно согласуется с трактовкой предмета правового регулирования в теории права. С.С. Алексеев определяет его как «разнообразные общественные отношения, которые объективно по своей природе могут «поддаваться» нормативно-организационному воздействию и в данных социально-политических условиях тре- буют такого воздействия, осуществляемого при помощи юридических норм, всех иных юридических средств, образующих механизм правового регулирования» [1, с. 292]. Вопрос о содержании предмета уголовного права не рассматривается в настоящей статье, главное при сопоставлении двух дефиниций, что обращает на себя внимание - соблюдение соотношения категорий общего и особенного, где отраслевое понятие предмета отражает общетеоретическое его понимание.

В сравнительном плане рассмотрим некоторые другие варианты определения предмета уголовного права, предлагаемые в литературе. Несколько более узкую трактовку предмета уголовного права предлагает Ю.Е. Пудовочкин, определяя его как «возникающие с момента совершения преступления и на основе уголовно-правовых норм общественные отношения, складывающиеся между государством в лице его компетентных органов и лицом, совершившим преступление» [13, с. 59-60]. С одной стороны, в таком понимании предмета уголовного права конкретизируется его содержание, а с другой, в отличие от определения Н.В. Генрих, в нем не нашлось места общим признакам предмета правового регулирования. Кроме того, значительный пласт регулируемых уголовным правом (точнее говоря, охраняемых уголовным правом) отношений не подпадает под подобное понимание предмета отрасли уголовного права.

B.В. Мальцев не ограничивается понятием предмета уголовно-правового регулирования, он оперирует терминами «предмет уголовного права», «предмет уголовно-правовой охраны». Последнее представляет особый интерес, важен акцент ученого на запретительном характере уголовно-правовых норм, а также на регулировании общественных отношений путем такого способа правового регулирования, как уголовно-правовой запрет [10, с. 68-81]. Несмотря на ряд нюансов, связанных с включением в предмет уголовного права ряда феноменов, относящихся, скорее, к объекту исследования уголовно-правовой науки, содержательную сторону определения предмета уголовно-правового регулирования (равно как и уголовно-правовой охраны), предлагаемую В.В. Мальцевым, следует признать интересной и в значительной степени адекватной общетеоретическому пониманию предмета отрасли права. Такое понимание, во-первых, отражает запретительную специфику уголовно-правовых норм, т.е. учитывает, что наиболее значительный пласт уголовно-правового регулирования осуществляется посредством уголовно-правового запрета, а также, что наиболее желательной формой правового поведения в уголовно-правовой сфере является соблюдение уголовно-правовых запретов. Во-вторых, предмет уголовного права достаточно чётко отграничивается от предметов иных правовых отраслей. В-третьих, опре- 
деление предмета осуществляется с учетом специфики метода уголовно-правового регулирования.

Аналогичную дуалистическую трактовку предлагает И.Я. Козаченко, определяя предмет уголовно-правового регулирования. Ученый указывает на то, что уголовное право охраняет два предмета: «первый - наиболее важные для общества отношения между людьми независимо от сферы человеческой деятельности, в том числе управленческой, имущественной, духовной и т.д. (предмет уголовно-правовой охраны); второй — отклоняющиеся (аномальные) отношения, противоречащие интересам не только отдельных граждан, но и обществ в целом (предмет уголовно-правовой реанимации)» [8, с. 7]. В другой работе И.Я. Козаченко указывает, что «структурными элементами предмета уголовного права выступают горизонтальные (линейные) отношения (человек - преступление - ответственность) и вертикальные (иерархические) отношения (государство - преступник - наказание)» [7, с. 89].

Особо необходимо отметить позицию А.И. Бойцова, который, наряду с раскрытием собственного видения содержания предмета уголовно-правового регулирования, определяет это понятие. «Предмет уголовно-правового регулирования можно определить как социальные отношения, обеспечивающие состояние защищенности жизненно важных интересов личности, общества, государства, сообщества государств и всего человечества от преступных посягательств» $[15$, с. 11]. Помимо того, что такое определение полностью соответствует предусмотренным ч. 1 ст. 2 УК РФ задачам уголовного кодекса, оно ещё и показывает, что защищается уголовно-правовыми средствами, и от чего.

Затронем также подход А.Э.Жалинского, который определение предмету уголовного права не дает, но очень точно характеризует его содержание: а) запрещенное правом поведение право- и дееспособных индивидов и юридических лиц, противоречащее или могущее противоречить реальным или предполагаемым интересам общества или группы, субъекта, осуществляющего законодательную власть; б) деятельность управомоченных субъектов по уголовному правоприменению, в частности, устанавливающая интеллектуальные правила применения норм об основаниях уголовной ответственности [6, с. 81]. К достоинствам такого подхода можно отнести как соответствие общему пониманию предмета отраслевого правового регулирования, так и определение специфики предмета уголовного права. При этом определяемые им группы отношений, составляющие предмет уголовно-правового регулирования, с учетом представленных в литературе позиций, также можно подразделить на, условно говоря, «общие» отношения, или «отношения по общему правилу», и «отношения-исключения».
Первая группа отношений, исходя из этого, включает в себя, помимо запрещенных образцов поведения, ещё и такие, которые формально являются запрещенными, но в силу тех или иных причин в конкретном случае разрешаются. Речь идет о т.н. непреступных уголовно-правовых деяниях [3, с. 15]. В рамках второй группы отношений А.В. Денисова предлагает различать деятельность по привлечению лиц, совершивших преступления, к уголовной ответственности, и деятельность по применению к невменяемым, совершившим общественно опасные деяния, принудительных мер медицинского характера, а к не достигшим возраста уголовной ответственности - принудительных мер воспитательного воздействия (урегулирование последней группы общественных отношений вызывает особую группу уголовно-правовых отношений - патерналистские отношения) $[5$, с. 31-32].

Ключевое явление и понятие о нем, определяющее отраслевой статус уголовного права - предмет уголовно-правового регулирования (предмет уголовного права) на сегодняшний день в уголовно-правовой науке определяется с разных позиций. Преимущественная точка зрения, адекватная общему понятию предмета правового регулирования, понимает предмет через общественные отношения, которые, в зависимости от правового режима, либо охраняются уголовным правом, либо им регулируются, то есть уголовное право либо закрепляет негативные образцы поведения (запрещая их), либо определяет программу действий правоохранительных органов в случае нарушения такого запрета. При этом и первые и вторые предполагают исключения. Уголовное право отдельно регулирует случаи, когда причинение уголовно наказуемого вреда правомерно, а также случаи, когда совершаемое общественно опасное деяние не может быть признано преступлением, но необходимо применение государственного принуждения. Подчеркнем: речь во всех случаях идет именно о регулировании, а не о воздействии, уголовно-правовой запрет, или негативное обязывание - это точно такой же способ правового регулирования [12, с. 41], как и позитивное обязывание, или дозволение. Ещё одним выводом будет выступать очевидная, впрочем, тесная взаимосвязь предмета с методом уголовно-правового регулирования. Именно характер инструментария определяет задачу, которую он сможет решить. Если предмет уголовно-правового регулирования образует объективная социальная реальность, то метод составляет сущность и содержание уголовного права. Кроме того, в уголовно-правовой науке России понятие уголовного права большинством авторов определяется не через предмет этой отрасли (как, например, в гражданском праве), а через ее метод. Это обстоятельство, на наш взгляд, составляет особенное в понимании отрасли уголовного права, вполне укладывающееся в рамки общего понимания отрасли права. 


\section{ЛИТЕРАТУРА}

1. Алексеев С.С. Общая теория права: в 2-х т. Т. І. М.: Юрид. лит., 1981. 360 с.

2. Бавсун М.В. Проблемы определения содержания предмета и метода уголовного права в условиях современной концепции развития общественных отношений // Всероссийский криминологический журнал. 2020. Т. 14, № 4. С. 570-580.

3. Гарбатович Д.А. Квалификация непреступных уголовно-правовых деяний. М.: Юрлитинформ, 2017. 320 с.

4. Генрих Н.В. Предмет и метод уголовно-правового регулирования: история, теория и практика. М.: Норма: ИНФРА-М, 2016. 318 С.

5. Денисова А.В. Системность российского уголовного права. М.: Юрлитинформ, 2018. 512 с.

6. Жалинский А.Э. Избранные труды. В 4 т. Т. 2. Уголовное право / сост. К.А. Барышева, 0.Л. Дубовик, И.И. Нагорная, А.А. Попов; отВ. ред. 0.Л. Дубовик. М.: Изд. дом ВШЭ, 2015.591 c.

7. К Козаченко И.Я. Предмет уголовного права: содержание и структура // Российский юридический журнал. 2012. № 6 (87). С. 80-90.

8. Козаченко И.Я. Уголовное право России. Общая часть. Визуально-аналитический рецепт. М.: Юрлитинформ, 2021. 256 с.

9. Конфуций. Изречения. Книга песен и гимнов: пер. с др.-кит. М.: АСТ: Астрель, 2011. 506 с.

10. Мальцев В.В. Предмет и метод уголовного права // Известия высших учебных заведений. Правоведение. 2004. № 4. С. 68-81.

11. Протасов В.Н. Теория права и государства. Проблемы теории права и государства. М.: Новый юрист, 1999. 234 с.

12. Прохоров В.С., Кропачев Н.М., Тарбагаев А.Н. Механизм уголовно-правового регулирования: норма, правоотношение, ответственность. Красноярск: Издво Краснояр. ун-та, 1989. 208 с.

13. Пудовочкин Ю.Е. Учение об основах уголовного права: лекции. М.: Юрлитинформ, 2012. 240 с.

14. Синюков В.Н. Российская правовая система. Введение в общую теорию. 2-е изд., доп. М.: Норма, 2010. 672 с.

15. Уголовное право России. Общая часть / под ред. В.В. Лукьянова, В.С. Прохорова, В.Ф. Щепелькова. 3-е изд., испр. и доп. СПб.: Изд-во С.-Петерб. ун-та, 2018. $628 \mathrm{c}$.

16. Филимонов В.Д. Охранительная функция уголовного права. СПб.: Юридический центр Пресс, 2003. 198 с.

17. Фуко М. Надзирать и наказывать: Рождение тюрьмы. М.: Ад Маргинем Пресс, 2015. 416 с.

18. Энциклопедия уголовного права. В 35 т. Т. 1. Понятие уголовного права / отВ. ред. В.Б. Малинин. СПб.: СПб ГКА, издание профессора Малинина, 2005.700 с.

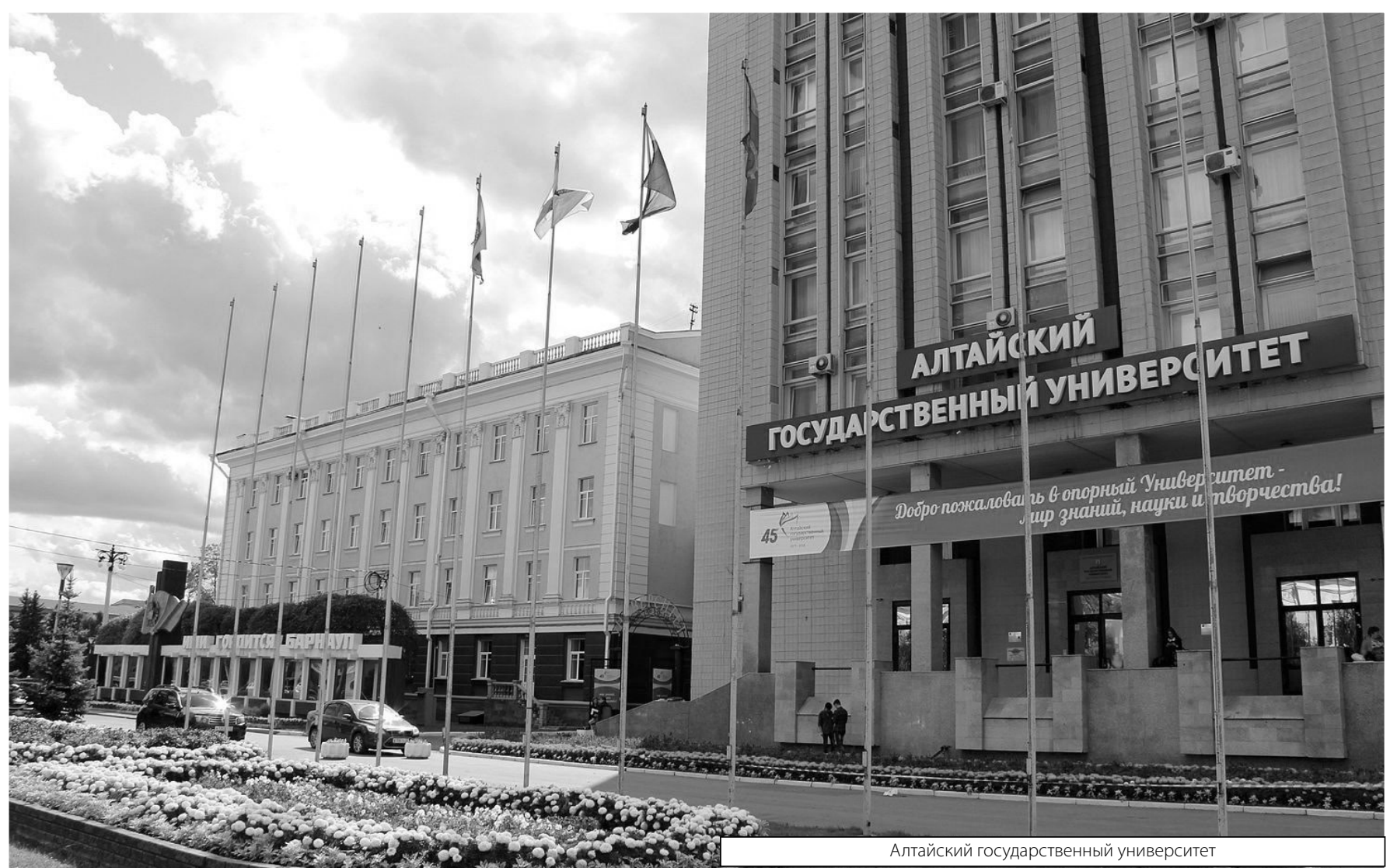

